\title{
Human induced dryland degradation in Ordos Plateau, China, revealed by multilevel statistical modeling of normalized difference vegetation index and rainfall time-series
}

\author{
Jing ZHANG ${ }^{1,2}$, JianMing NIU ${ }^{1,3^{*}}$, Tongliga BAO ${ }^{4}$, Alexander BUYANTUYEV ${ }^{1,3,5}$, Qing ZHANG ${ }^{1}$, \\ JianJun DONG ${ }^{1}$, XueFeng ZHANG ${ }^{1}$ \\ ${ }^{1}$ College of Life Sciences, Inner Mongolia University, Hohhot 010021, China; \\ ${ }^{2}$ College of Environment and Resources, Dalian Nationalities University, Dalian 116600, China; \\ ${ }^{3}$ Sino-US Center for Conservation, Energy, and Sustainability Science, Inner Mongolia University, Hohhot 010021, China; \\ ${ }^{4}$ Faculty of Resources and Environment, Baotou Teachers College, Baotou 014030, China; \\ ${ }^{5}$ Department of Botany and Plant Sciences, University of California, Riverside CA 92521, USA
}

\begin{abstract}
Land degradation causes serious environmental problems in many regions of the world, and although it can be effectively assessed and monitored using a time series of rainfall and a normalized difference vegetation index (NDVI) from remotely-sensed imagery, dividing human-induced land degradation from vegetation dynamics due to climate change is not a trivial task. This paper presented a multilevel statistical modeling of the NDVI-rainfall relationship to detect human-induced land degradation at local and landscape scales in the Ordos Plateau of Inner Mongolia, China, and recognized that anthropogenic activities result in either positive (land restoration and re-vegetation) or negative (degradation) trends. Linear regressions were used to assess the accuracy of the multilevel statistical model. The results show that: (1) land restoration was the dominant process in the Ordos Plateau between 1998 and 2012; (2) the effect of the statistical removal of precipitation revealed areas of human-induced land degradation and improvement, the latter reflecting successful restoration projects and changes in land management in many parts of the Ordos; (3) compared to a simple linear regression, multilevel statistical modeling could be used to analyze the relationship between the NDVI and rainfall and improve the accuracy of detecting the effect of human activities. Additional factors should be included when analyzing the NDVI-rainfall relationship and detecting human-induced loss of vegetation cover in drylands to improve the accuracy of the approach and eliminate some observed non-significant residual trends.
\end{abstract}

Keywords: NDVI-rainfall relationship; anthropogenic activities; multilevel statistical modeling; land degradation; dryland; Ordos Plateau

Citation: Jing ZHANG, JianMing NIU, Tongliga BAO, Alexander BUYANTUYEV, Qing ZHANG, JianJun DONG, XueFeng ZHANG. 2014. Human induced dryland degradation in Ordos Plateau, China, revealed by multilevel statistical modeling of normalized difference vegetation index and rainfall time-series. Journal of Arid Land, 6(2): 219-229. doi: 10.1007/s40333-013-0203-x

Land degradation, defined as a reduction in the biological productivity of land arising from climate change and human activities (Reynolds et al., 2002), is a serious environmental problem (UNCED, 1992). Arid ecosystems support the livelihood of communities and maintain important ecological processes in fragile drylands (Reynolds et al., 2007). It is estimated that $10 \%$ to $20 \%$ of drylands have undergone severe degradation, which has directly affected more than 250 million people in developing countries (UNCCD, 1994).

Land degradation is a product of the interplay be-

${ }^{*}$ Corresponding author: JianMing NIU (E-mail: jmniu2005@163.com)

Received 2013-05-02; revised 2013-07-24; accepted 2013-08-16

(C) Xinjiang Institute of Ecology and Geography, Chinese Academy of Sciences, Science Press and Springer-Verlag Berlin Heidelberg 2014 
tween climatic factors and human activities (Adamo et al., 2006). Dryland areas require to be monitored to understand the mechanisms of land degradation to enable land managers and policy-makers to combat this unwanted process and develop strategies for the efficient use of resources and the overall ecological sustainability of drylands (Pickup, 1996). Land degradation dynamics and their driving factors are commonly studied by time-series analyses of remotely-sensed data and regression modeling (Zang et al., 2006; Millington et al., 2007). However, distinguishing human-induced land degradation from naturally occurring vegetation dynamics in response to climate fluctuation has been a challenging task (Nicholson et al., 1998; Geerkena et al., 2004). One approach to separate human activities from climatic influences on vegetation dynamics has been the use of the relationship between the normalized difference vegetation index (NDVI) and rainfall (Wessels et al., 2007). This methodology utilizes changes in NDVI, a proxy for vegetation biomass, which has been repeatedly found to respond to precipitation. Human-induced land degradation can be separated from vegetation changes due to inter-annual precipitation variations using the recently proposed residual trends analysis (RESTREND; Evans et al., 2004). Residuals are first computed by subtracting predicted NDVI values from the observed NDVI, and then trend lines are fitted to the time-series of these residuals. If trends are identified for residuals, they are attributed to human-induced land cover changes (Wessels et al., 2007). This approach has been successfully used to project human activities in South Africa and China (Wessels et al., 2007; Li et al., 2012).

The relationship between precipitation and NDVI has usually been estimated by a Simple Linear Regression (SLR). However, a simplified linear assumption may often not be true because of the complex interaction between vegetation and precipitation. To alleviate this shortcoming, Omuto et al. (2010) present a mixed-effect modeling method, which can simultaneously model individual NDVI-rainfall fits for different vegetation types. This method is more accurate in detecting areas with human-induced loss of vegetation cover compared to a single global model. It is important to recognize that the role of both precipitation and human activities in driving ecological processes in drylands will change with scales (Wu et al., 2006), and clarity is required when addressing such a multiplicity of scales. For example, the NDVI response to precipitation should be analyzed at both an annual scale (e.g. annual precipitation variations) and a longer time period (e.g. multi-year trends among vegetation types) (Verbesselt et al., 2010). Focusing on a single scale has been the major shortcoming of previous studies that have employed this modeling approach. Multilevel statistical models (MLM), which nest hierarchical structures of data and models (Serneels et al., 2007), are a promising approach to understand NDVI-rainfall relationships of different scales simultaneously.

The Ordos Plateau in Inner Mongolia autonomous region of China was chosen to apply the multilevel statistical modeling to account for the complex interactions between vegetation and climate. Specifically, spatial patterns in the region were analyzed as a 2-level nested hierarchy of local and landscape scales. It was hypothesized that NDVI dynamics can be simultaneously modeled at two levels: (1) fluctuations at the local scale controlled by human activities and annual precipitation; (2) slow changes due to longterm precipitation periodicity at the landscape level, modeled as a linear trend for different vegetation types. The objectives were: (1) to assess how multilevel statistical models can improve the modeling of NDVIrainfall relationships and detect human-induced vegetation changes; and (2) to evaluate the effect of human activities on vegetation cover dynamics using longterm remote sensing and precipitation data.

\section{Study area and data analysis}

\subsection{Study area}

The Ordos Plateau (hereafter referred to as Ordos, $37^{\circ} 41^{\prime} \mathrm{N}-40^{\circ} 51^{\prime} \mathrm{N}$; $106^{\circ} 42^{\prime} \mathrm{E}-111^{\circ} 31^{\prime} \mathrm{E}$ ) is located in the southwest region of Inner Mongolia, China (Fig. 1). It covers an area of $87,400 \mathrm{~km}^{2}$. The climate is temperate continental with an annual mean temperature of $5.3^{\circ} \mathrm{C}$ to $8.7^{\circ} \mathrm{C}$, with 2,716 to 3,194 hours of annual sunshine and an annual mean precipitation gradient of $150 \mathrm{~mm}$ in the west to $450 \mathrm{~mm}$ in the east. Most precipitation occurs from June to September. Annual evaporation increases from $2,000 \mathrm{~mm}$ in the east to $3,000 \mathrm{~mm}$ in the west. Dominant soil types in the region are kas- 
tanozems, calcic brown soil, and aeolian sandy soil. Four major vegetation types have been developed in the Ordos: typical steppe, desert steppe, sandy land (Mu Us Sandy Land), and desert (Hobq Desert). The growing season occurs between April and October, with primary vegetation production reaching its annual peak between June and August. Traditional land uses have been livestock husbandry (in most parts of the Ordos) and farming (in some areas along Yellow River, Jungar and Uxin), a typical combination in the agro-

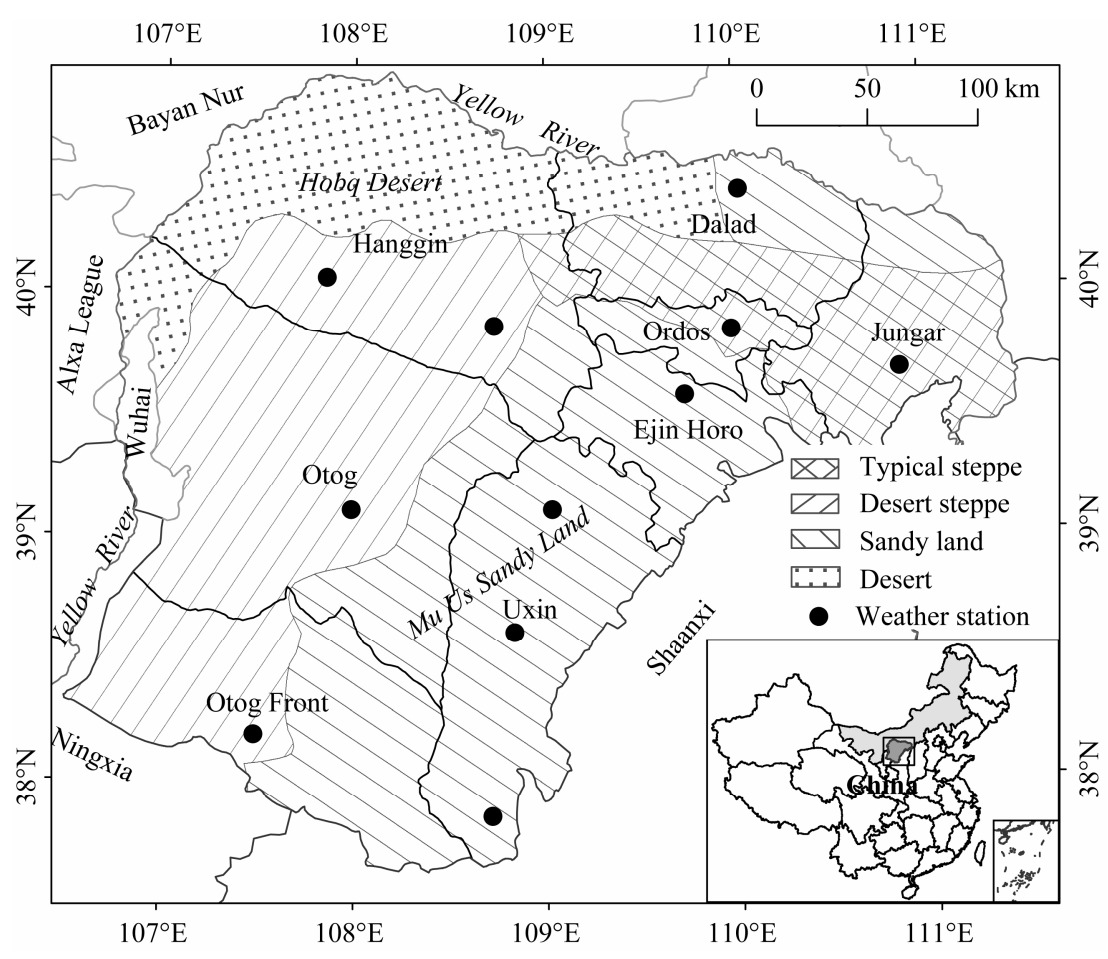

Fig. 1 Location map of the Ordos Plateau

pastoral transitional zone of northern China.

\subsection{Regression analysis of NDVI-rainfall rela- tionship}

Multilevel statistical modeling (MLM) was designed to deal with hierarchically-structured (nested and clustered) data (Goldstein, 2003). Variables at the level of individuals (lower level) can be partly explained by a variation at the individual level and partly by a variation at the group level (higher level) (Snijders et al., 1999). The modeling process starts with an empty (or intercept-only) model defined as follows:

$$
\begin{aligned}
& y_{i j}=\beta_{0 j}+\varepsilon_{i j}, \\
& \beta_{0 j}=\gamma_{00}+u_{0 j} .
\end{aligned}
$$

Where $i$ denotes indices at level $1 ; j$ denotes indices at level $2 ; y_{i j}$ is the dependent variable at level $1 ; \beta_{0 j}$ is the intercept of $j_{t h}$ group (higher level); $\varepsilon_{i j}$ is $i_{t h}$ random variation associated with $j_{t h}$ group; $\gamma_{00}$ is the overall intercept for both levels; $u_{0 j}$ is the group dependent deviation. The following model (Eqs. 3 and 4) is called a mixed model since it includes level 1 and 2 explanatory variables. Equations 3 and 4 can be rewritten into a combined, or composition model (Eq. 5):

$$
\begin{gathered}
y_{i j}=\beta_{0 j}+\sum_{p=1}^{P} \alpha_{p} x_{p i j}+\sum_{q=1}^{Q} \beta_{q j} z_{q i j}+\varepsilon_{i j}, \\
\beta_{0 j}=\gamma_{00}+\sum_{m=1}^{M} \gamma_{0 m} w_{m j}+u_{0 j}, \\
\beta_{1 j}=\gamma_{10}+\sum_{m=1}^{M} \gamma_{1 m} w_{m j}+u_{1 j}, \\
\ldots, \\
\beta_{Q j}=\gamma_{Q 0}+\sum_{m=1}^{M} \gamma_{Q m} w_{m j}+u_{Q j}, \\
y_{i j}=\gamma_{00}+\sum_{m=1}^{M} \gamma_{0 m} w_{m j}+\sum_{p=1}^{P} \alpha_{p} x_{p i j}+\sum_{q=1}^{Q} \gamma_{q 0} z_{q i j}+ \\
\sum_{q=1}^{Q} \sum_{m=1}^{M} \gamma_{q m} w_{m j} z_{q i j}+\left(u_{0 j}+\sum_{q=1}^{Q} z_{q i j} u_{q j}+\varepsilon_{i j}\right) .
\end{gathered}
$$


Where $x_{p i j}$ are level $1 P$ explanatory variables with fixed effects (or fixed slope) and $z_{q i j}$ are level $1 Q$ explanatory variables with random effects (or random slope); $\alpha_{p}$ are fixed slopes of level 1 explanatory variables; $\beta_{0 j}$ is the random intercept at level $1 ; \beta_{Q j}$ are random slopes at level 1 that correspond to response variables explained by level 2 explanatory variables $w_{m j} ; w_{m j}$ are level $2 M$ explanatory variables.

An intra-class correlation coefficient (ICC) is used to estimate the proportion of variance among group (higher) levels. Lower ICC means a lower degree of similarity of measurements within a group. Equation 6 shows the calculation of ICC for the 2-level model.

$$
I C C=\frac{\sigma_{b}^{2}}{\sigma_{w}^{2}+\sigma_{b}^{2}} .
$$

Where $\left(\sigma_{w}^{2}+\sigma_{b}^{2}\right)$ is the total variance of the multilevel model; $\sigma_{w}^{2}$ is within-group variation or variance at level 1 (individual level); $\sigma_{b}^{2}$ is level 2 betweengroup variations or variances at the group level (higher level). ICC is the ratio of between-group variation and total variance.

Similar to $R^{2}$ in the Ordinary Least Squares (OLS) regression, the approximate $R_{1}^{2}$ and $R_{2}^{2}$ were used to estimate the proportion of explained variance at levels 1 and 2 (Raudenbush et al., 2002):

$$
\begin{gathered}
R_{1}^{2}=\frac{\sigma_{e \mid n}^{2}-\sigma_{e \mid m}^{2}}{\sigma_{e \mid n}^{2}}, \\
R_{2}^{2}=\frac{\sigma_{u|| n}^{2}-\sigma_{u 0 \mid m}^{2}}{\sigma_{u \mid n}^{2}} .
\end{gathered}
$$

Where $\sigma_{e \mid n}^{2}$ and $\sigma_{e \mid m}^{2}$ are the residual variances for empty model and estimated model at level 1, respectively; $\sigma_{u \mid n}^{2}$ and $\sigma_{u \mid m}^{2}$ are group variances for empty model and estimated model, respectively.

To test our hypothesis, we fit a 2-level model in which NDVI is explained by annual precipitation fluctuations (hereafter referred to as Rainfall $l_{\text {annual }}$ ) at the local scale, and gradual changes due to long-term precipitation periodicity (hereafter referred to as Rainfall $_{\text {mean }}$ ) at the landscape level for each vegetation type were derived using a wavelet analysis. Therefore, the full multi-level model (Eq. 11) is a combination of Eqs. 9 and 10.

$$
\begin{aligned}
& N D V I_{i j}= \beta_{0 j}+\beta_{1} \text { Rainfall }+\varepsilon_{i j}, \\
& \beta_{0 j}=\gamma_{00}+\gamma_{01} \text { Rainfall }_{\text {mean }}+u_{0 j}, \\
& N D V I_{i j}= \gamma_{00}+\gamma_{01} \text { Rainfall }_{\text {mean }}+ \\
& \beta_{1} \text { Rainfall }+\left(u_{0 j}+\varepsilon_{i j}\right) .
\end{aligned}
$$

A simple linear regression (SLR) was used to analyze trends (slopes) in the time series of NDVI by regressing it on years and comparing the results of MLM with the original residual trends analysis (RESTREND) method. SLR is described as follows:

$$
y=a+b x
$$

Where $y$ is dependent variable; $x$ is independent variable; $a$ is the intercept and $b$ is slope of this function.

\subsection{Detecting human induced loss/gain of vegeta- tion cover}

RESTREND method was proposed to separate human-induced land degradation from vegetation changes (Evans and Geerken, 2004; Wessels et al., 2007). This approach is specifically designed for arid and semi-arid regions (Nemani et al., 2003), where water availability is the primary limiting factor of the ecosystem processes (Huxman et al., 2004). A significant difference between the observed NDVI and predicted NDVI by precipitation (NDVI-rainfall relationship) is considered to be the likely anthropogenic contribution to vegetation cover change. Positive trends of residuals are identified as human-induced land cover improvement, while negative values represent the degeneration of vegetation (Wessels et al., 2007).

In this paper, both MLM and SLR methods were applied to estimate the NDVI-rainfall relationship and show how the multilevel statistical model (hereafter referred to as MLM-Restrend) can improve the accuracy compared to the commonly-applied simple linear regression model on NDVI and rainfall implemented in RESTREND (hereafter referred to as SLRRestrend). The MLM and SLR were compared using a simple linear regression (Eq. 12) of residual trends.

\subsection{Data sources and processing}

Ten-day SPOT VEGETATION NDVI maximum composite images with the spatial resolution of $1 \mathrm{~km}$ were acquired for the time period between 1998 and 2012 from the Flemish Institute for Technological Research (Vito) using the website http://free.vgt.vito.be/. 
These data were subset using the administrative boundary map of the Ordos. Composite NDVI (hereafter referred to as $\Sigma$ NDVI) was used to eliminate noise and atmospheric effects (Wessels et al., 2007) by integrating NDVI over the entire growing season (April to October, $n=21$ ).

Precipitation data was obtained from the Inner Mongolia Meteorological Bureau. We used monthly records from 11 weather stations for the period from 1998 to 2012 and interpolated the sum of the annual growing season precipitation to the whole study area at a resolution of $1 \mathrm{~km} \times 1 \mathrm{~km}$ by employing spherical semivariogram models and ordinary kriging. A wave- let analysis (Morlet wavelet as a mother function) was used to detect precipitation periodicity in Matlab 2012a, and the Rainfall mean was summarized based on the precipitation periodicity and average vegetation types.

For the landscape level analysis, we used a detailed vegetation map from the series of resource maps of Inner Mongolia autonomous region (1991) at a scale of 1:500,000, which was reclassified into 18 vegetation classes for modelling the NDVI-rainfall relationship in this area (Table 1). This vector map was converted into a raster format with the resolution of $1,000 \mathrm{~m}$.

Table 1 Vegetation classes at landscape level used in 2-level multilevel statistical model

\begin{tabular}{|c|c|c|c|}
\hline Code & Vegetation zone & Vegetation type & $\begin{array}{l}\text { Area percentage } \\
\qquad(\%)\end{array}$ \\
\hline 1 & $\begin{array}{l}\text { Typical steppe of bunchgrass and } \\
\text { rhyzomegrass }\end{array}$ & Stipa krylovii or Glycyrrhiza uralensis steppe & 2.01 \\
\hline 2 & \multirow{2}{*}{$\begin{array}{l}\text { Desert steppe of semi-shrub of short } \\
\text { bunchgrass and dwarf }\end{array}$} & Stipa goblic, S. Kerrpenzii, Cleistogens songorica deset steppe & 1.65 \\
\hline 3 & & Stipa gobica, S. glareosa and Caragana tibetica shrubby desert steppe & 6.90 \\
\hline 4 & \multirow{2}{*}{ Grasses and semi-shrubs steppe } & Stipa bungeana, Lespedeza davurica steppe & 2.38 \\
\hline 5 & & Thymus steppe & 4.88 \\
\hline 6 & $\begin{array}{l}\text { Desert steppe of short grasses and } \\
\text { small semi-shrubs }\end{array}$ & Stipa breviflora steppe & 0.62 \\
\hline 7 & \multirow{3}{*}{$\begin{array}{l}\text { Psammophyllous vegetation in } \\
\text { steppe zone }\end{array}$} & $\begin{array}{l}\text { Salix (S. mongolica, S. flavida, S. gordejevii, S. kochiana) and Hippo- } \\
\text { phae rhamnoides shrub }\end{array}$ & 0.26 \\
\hline 8 & & Artemisia ordosica psammophyllous semishrubs & 32.28 \\
\hline 9 & & Pioneer plants in moving dunes & 21.72 \\
\hline 10 & Steppefied desert & $\begin{array}{l}\text { Helianthemum soongoricum, Potaninia mongolica, Zygophyllum } \\
\text { xanthoxylon, Ammopiptanthus mongolicus }\end{array}$ & 5.18 \\
\hline 11 & Sandy desert & Artemisia sphaerocephala, Psammochloa villosa sandy desert & 4.31 \\
\hline 12 & Salt desert & Nitraria or Kalidium gracila, $K$. foliatum salt desert & 0.36 \\
\hline 13 & \multirow{3}{*}{ The vegetation of low and wet land } & Grasses sedges and forbs halophilic meadow & 7.72 \\
\hline 14 & & Achnatherum splendens halophilic meadow & 2.22 \\
\hline 15 & & Grasses and sedgs, marsh meadow or phragmites communis marsh & 0.78 \\
\hline 16 & \multirow{3}{*}{ Artificial vegetation } & Artificial (cultivated) forest (Populus, Salixr Ulmus and Pinus ) & 0.42 \\
\hline 17 & & Dry farming land & 2.37 \\
\hline 18 & & Irrigated farming land & 3.95 \\
\hline
\end{tabular}

Cloud-free Landsat-5 TM images with the spatial resolution of $30 \mathrm{~m}$ in the growing seasons of 2000 and 2011 were used to test the accuracy of the two statistical methods. These images were obtained from the website http://glovis.usgs.gov/. Vegetation loss and recovery were detected from land cover changes between the two time periods. Vegetation recovery was associated with vegetation planting near or around cities and towns, roads and farmlands, and vegetation loss was observed in areas of open-pit mining opera- tions and settlement expansions.

Multilevel statistical models were constructed for all pixels using a MIXED procedure of SAS 9.2 (Singer, 1998) and the REML (Restricted Maximum Likelihood) method. A Wald Z-test was used to determine the significance of coefficients, and a Spatial Analysis extension of ArcGIS 10.0 was used to create raster grids from this modeling. The significance of the simple linear regression analyses was assessed by a t-test using a two-tail t-distribution at a $95 \%$ confi- 
dence interval.

\section{Results}

\section{1 $\Sigma$ NDVI trends in the Ordos Plateau}

The results of the regression between $\Sigma$ NDVI and the corresponding year (Fig. 2a) revealed that $65.9 \%$ of the regression slopes were statistically significant (two-tail t-distribution at a 95\% confidence interval). Spatial vegetation cover increased throughout the east Ordos (slope 0.1-0.2), weakly increased in limited areas in the north and middle of the Ordos (slope $0-0.1$ ), and did not change in some parts of the west Ordos desert and desert steppe area (Fig. 2a). The spatial patterns of the coefficient of determination $\left(R^{2}\right)$ of $\Sigma$ NDVI trends (Fig. 2b) corroborate those in Fig. 2a. The strongest $\Sigma$ NDVI trends $\left(R^{2}>0.6\right)$ were in northern and eastern Ordos, but they were very low $R^{2}(0-0.2)$ in the west Ordos desert and desert steppe area.

\subsection{NDVI-rainfall relationship modeling}

The wavelet coefficient contours of mean annual growing season precipitation were aggregated at about 7-8 and 13-14 years scales (Fig. 3a). Wavelet variances (Fig. 3b) exhibited maxima at the 8-year scale suggesting that the principal periodicity of growing season precipitation was approximately 3-4 years. Thus, the 15-year precipitation was divided into 6 stages (periodicity of 3 years) to analyze the Rainfall $_{\text {mean }}$ at the landscape level. A low precipitation season occurred in 1998-2001, 2005-2006, 2009-2011, while a wet period occurred in 2002-2004, 2007-2008, and 2012.

Several empty models were fitted to calculate ICCs, which measure the proportion of variance explained at the landscape levels. The ICCs of 2-level models explained more than $40 \%$ variance at the landscape level, respectively, indicating a similar NDVI-rainfall relationship for the same vegetation type (Table 2). A series of 2-level full models were estimated using Eqs. 9-11 (Table 2), to calculate the approximate $R_{1}^{2}$ and $R_{2}^{2}$ (Table 2) indicating the differences between models at the local level $(0.2 \%-39.9 \%)$ and landscape level $(12.3 \%-80.3 \%)$.

Examining residuals derived from an MLM-Restrend analysis, which removes the precipitation effects, is beneficial for identifying areas of human-induced vegetation changes $(42.53 \%$ of slopes is statistically significant, Fig. 4a). It is evident that, during the study period (1998-2012), human activities in the Ordos Plateau resulted in an increase of vegeta-
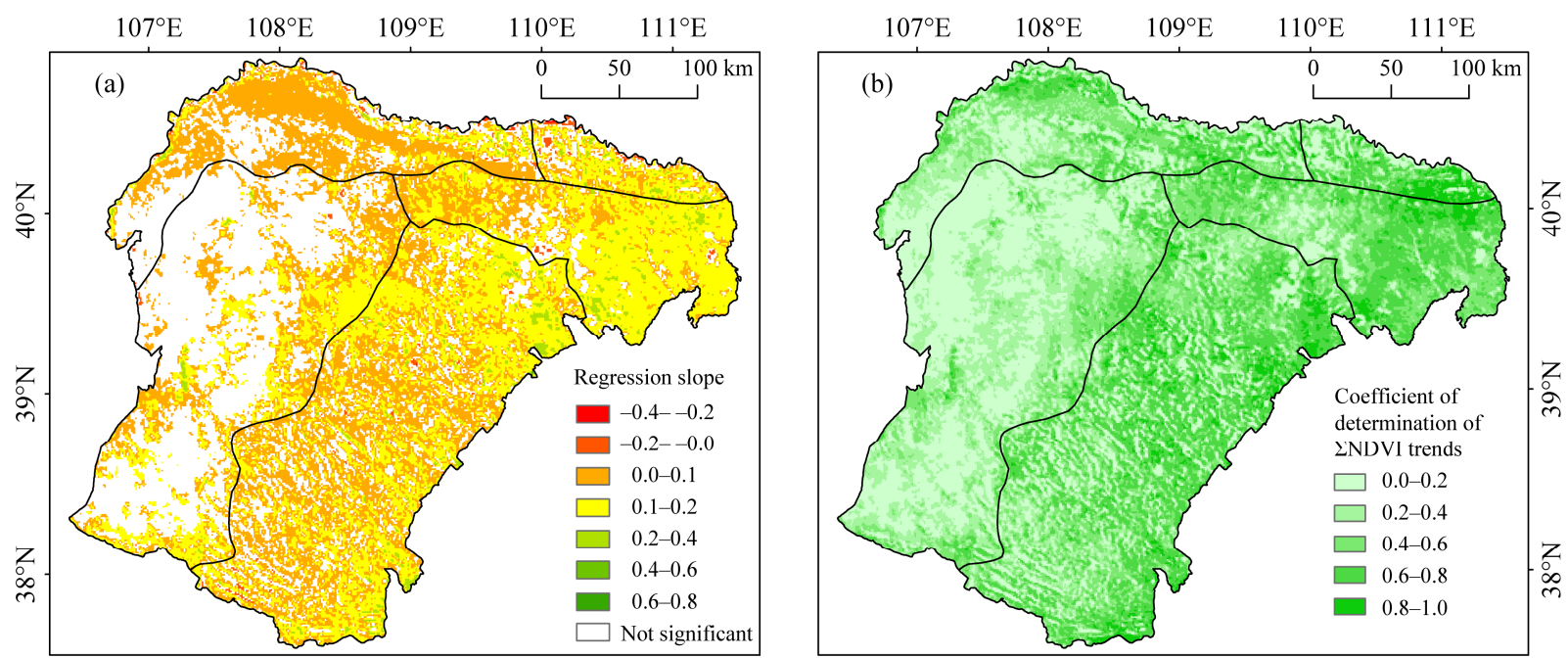

Fig. $2 \sum N D V I$ trends in the Ordos Plateau. (a) Map of $\Sigma$ NDVI slope of NDVI-time regression (t-test, $95 \%$ confidence interval, no change areas are shown in white); (b) coefficient of determination $\left(R^{2}\right)$ of $\Sigma \mathrm{NDVI}$ trends. 

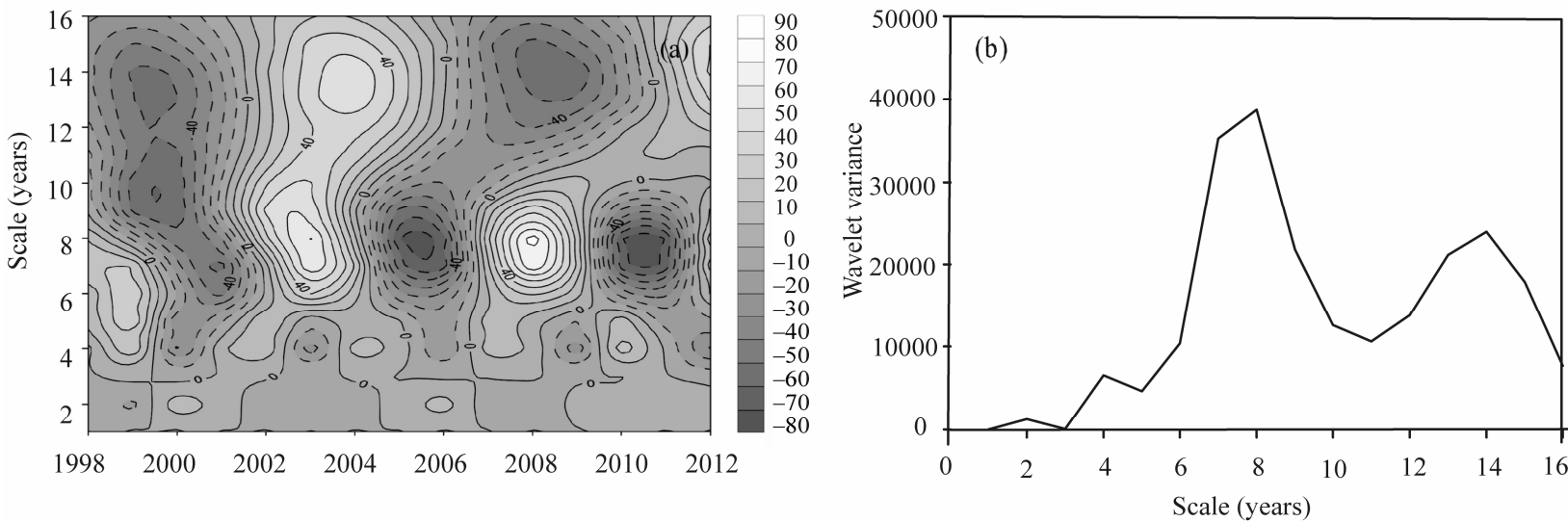

Fig. 3 NDVI-rainfall relationship modeling. (a) Wavelet coefficients contour map of mean annual growing season precipitation. Solid lines are positive values of wavelet coefficients; dashed lines are negative values of wavelet coefficients. This map displays precipitation fluctuations in the time series; (b) Wavelet variances of mean annual growing season precipitation.

tion cover (positive slopes of residuals, Fig.4a), while limited areas experienced vegetation cover decline due to human influence (Fig. 4a). Relatively higher regression slopes of residuals were observed in the typical steppe and sandy land areas (slope $>0.4$ ) of eastern Ordos, indicating human-generated re-vegetation. Lower values of positive slopes of residuals (0.1-0.2) were found in most parts of the Ordos except some desert and desert steppes, where slopes were non-significant. The map in Fig. 4b shows the goodness of fit of residual trends. They are low in the desert in the north-west of the Ordos $\left(R^{2}<0.2\right)$, but generally higher in the reminder of the plateau.

Figure 5 shows the results of the simple linear regression (SLR-Restrend) to estimate human-induced land degradation, which can be compared to that of the MLM estimated NDVI-rainfall relationship. The spatial distribution of the SLR-Restrend slopes is similar to that of the MLM. They are statistically significant in $63.67 \%$ of the study area except the western part of the desert and desert steppe (Fig. 5a), and mainly range from 0.1 to 0.2 . The determination coefficient of SLR-Restrend regressions is higher in eastern Ordos (Fig. 5b).

Table 2 Summary of model outputs for multilevel statistical models

\begin{tabular}{lcccccc}
\hline Year & ICC & $R_{1}^{2}$ & $R_{2}^{2}$ & Model output \\
\cline { 5 - 6 } & & 0.136 & 0.364 & 1.74360 & Slope at level 1 & Slope at level 2 \\
\hline 1998 & 0.448 & 0.051 & 0.613 & -0.17320 & 0.00046 & 0.00027 \\
1999 & 0.466 & 0.193 & 0.689 & 0.76610 & 0.0006109 & 0.00099 \\
2000 & 0.464 & 0.149 & 0.581 & -0.93620 & 0.00065 & 0.00029 \\
2001 & 0.506 & 0.064 & 0.123 & 2.06170 & 0.00027 & 0.00092 \\
2002 & 0.459 & 0.140 & 0.618 & 0.96640 & 0.00056 & 0.00036 \\
2003 & 0.487 & 0.178 & 0.653 & 0.90760 & 0.00067 & 0.00043 \\
2004 & 0.497 & 0.399 & 0.803 & -0.02155 & 0.00158 & 0.00039 \\
2005 & 0.552 & 0.170 & 0.717 & -1.72580 & 0.00089 & 0.00054 \\
2006 & 0.535 & 0.002 & 0.382 & -0.48330 & 0.00016 & 0.00132 \\
2007 & 0.485 & 0.242 & 0.651 & 0.50220 & 0.00089 & 0.00177 \\
2008 & 0.488 & 0.239 & 0.531 & -0.00595 & 0.00146 & 0.00040 \\
2009 & 0.492 & 0.297 & 0.672 & 1.05750 & 0.00111 & 0.00045 \\
2010 & 0.451 & 0.190 & 0.620 & -1.14430 & 0.00046 & 0.00013 \\
2011 & 0.472 & 0.120 & 0.381 & -1.73470 & 0.00123 & 0.00140 \\
2012 & 0.446 & & & & 0.00063 \\
\hline
\end{tabular}



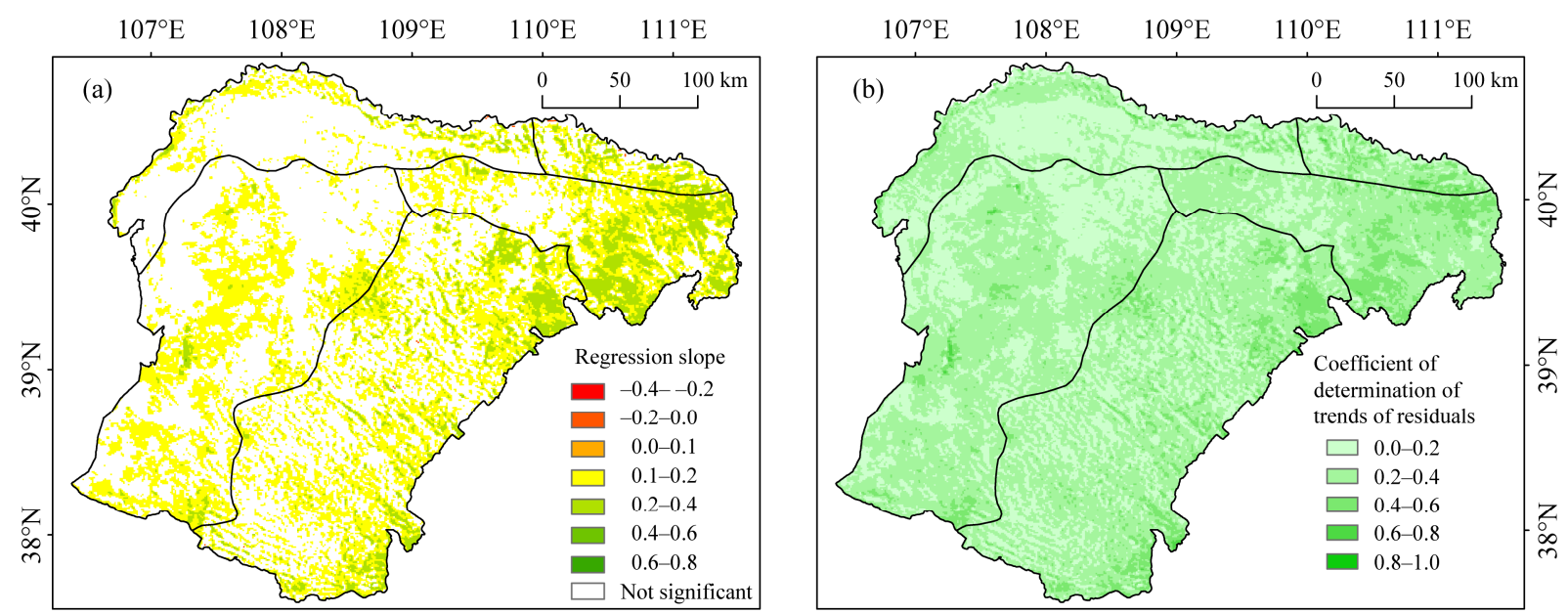

Fig. 4 Human-induced land degradation (trends of residuals) of the multilevel statistical modeling (t-test, 95\% confidence interval). (a) Negative regression slopes represent human-induced vegetation degradation, while positive slopes mean human-induced vegetation restoration. Non-statistically significant areas are shown in white; (b) coefficient of determination $\left(R^{2}\right)$ of human-induced land degradation (trends of residuals).
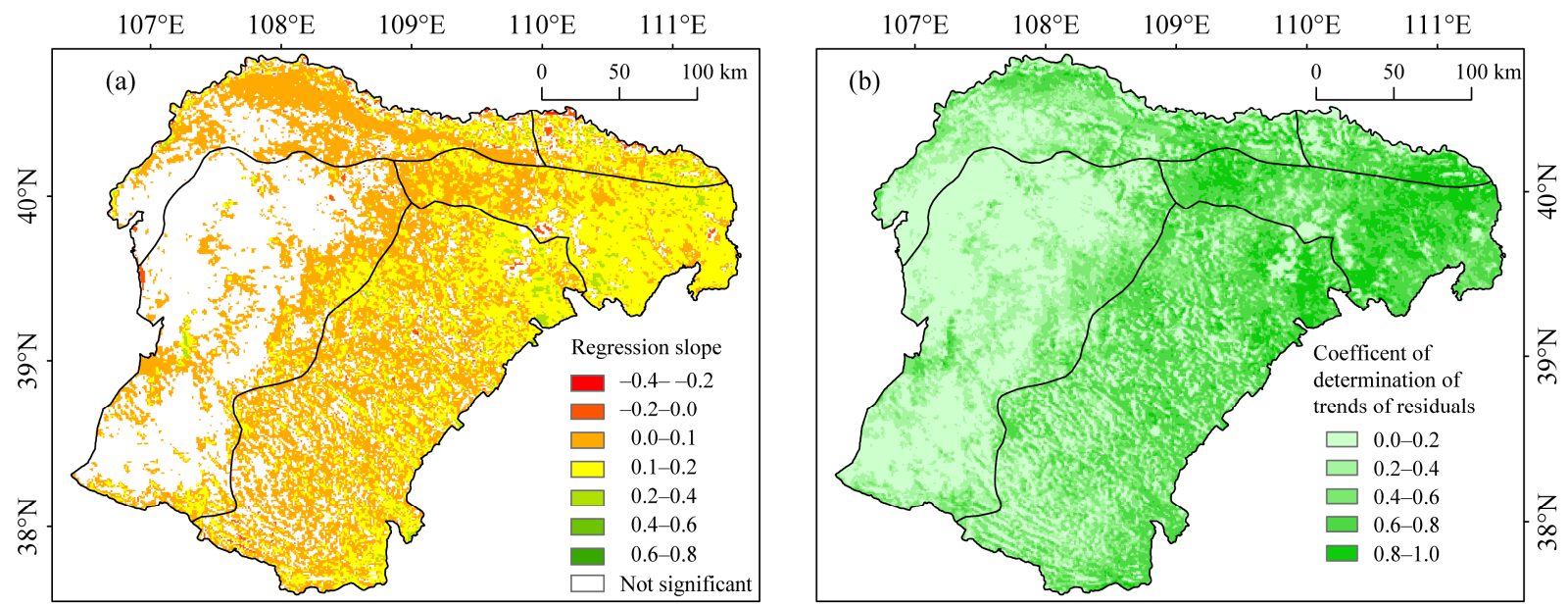

Fig. 5 Human-induced land degradation (trends of residuals) of the simple linear regression (t-test, 95\% confidence interval). (a) Negative regression slopes represent human-induced vegetation degradation, while positive slopes mean human-induced vegetation restoration. Non-statistically significant areas are shown in white; (b) coefficient of determination $\left(R^{2}\right)$ of human-induced land degradation (trends of residuals).

\subsection{Comparison of MLM-Restrend and SLR-Re- strend in predicting vegetation loss}

Seventy ground validation points were selected to compare the two regression methods. These points were classified into 6 groups: 1) vegetation loss due to urban expansion; 2) vegetation restoration accompanying urban expansion; 3) vegetation loss from road construction; 4) vegetation restoration from road construction; 5) vegetation loss from mining; and 6) vegetation restoration due to farming (Table 3). The MLM-Restrend was $80 \%$ accurate (56 correct identi- fications of human activities) while the SLR-Restrend was only $62 \%$ accurate (Table 3 ). The MLM-Restrend was more accurate in recognizing human activities such as vegetation restoration caused by urban expansion $(88 \%)$, vegetation restoration caused by road construction (91\%), vegetation loss caused by mining (79\%) and vegetation restoration caused by farming (75\%), while SLR-Restrend has better performances in detecting vegetation loss caused by urban expansion $(89 \%)$ and vegetation loss caused by road construction $(50 \%)$. 
Table 3 Accuracy of predicted human-induced vegetation loss or restoration predicted multilevel statistical models and ordinary least squares models

\begin{tabular}{|c|c|c|c|c|c|}
\hline Human activity type & $\begin{array}{l}\text { Total } \\
\text { validation } \\
\text { point }\end{array}$ & $\begin{array}{l}\text { Number of correct point } \\
\text { of MLM-Restrend } \\
\text { predicted human activ- } \\
\text { ity }\end{array}$ & $\begin{array}{l}\text { Percentage } \\
(\%)\end{array}$ & $\begin{array}{l}\text { Number of correct point } \\
\text { of SLR-Restrend pre- } \\
\text { dicted human activity }\end{array}$ & $\begin{array}{l}\text { Percentage } \\
\quad(\%)\end{array}$ \\
\hline Vegetation loss caused by urban expansion & 18 & 14 & 78 & 16 & 89 \\
\hline $\begin{array}{l}\text { Vegetation restoration caused by urban } \\
\text { expansion }\end{array}$ & 8 & 7 & 88 & 1 & 13 \\
\hline Vegetation loss caused by road construction & 4 & 1 & 25 & 2 & 50 \\
\hline $\begin{array}{l}\text { Vegetation restoration caused by road con- } \\
\text { struction }\end{array}$ & 22 & 20 & 91 & 14 & 64 \\
\hline Vegetation loss caused by mining & 14 & 11 & 79 & 9 & 64 \\
\hline Vegetation restoration caused by farming & 4 & 3 & 75 & 1 & 25 \\
\hline
\end{tabular}

\section{Discussion}

\subsection{Climatic driver of vegetation cover dynamics}

According to the $\Sigma$ NDVI trend analysis, vegetation cover increased throughout most of the Ordos Plateau during the period between 1998 and 2012. Although the annual growing season precipitation fluctuated significantly during the 15-year period (Figs. 3a and 6), it exhibited a positive trend (Fig. 6). Since SNDVI also exhibited significant positive trends throughout most of the Ordos during the same period (Fig. 2a), it is suggested that this increase of vegetation cover was partly driven by precipitation.

Different vegetation types had distinctive $\Sigma \mathrm{NDVI}$ slopes, which decreased from east to west, with no statistically significant slopes in the desert steppe area of the west Ordos (Fig. 2a). The NDVI of typical steppe and sandy land was strongly correlated with precipitation. This can be explained by the fact that the high production potential of typical water-limited steppes is realized to the fullest extent when water becomes available (Knapp et al., 2001; Nemani et al., 2003). On the other hand, the lower response of vegetation in sandy land to highly variable precipitation is explained by low vegetation density and substrates with high evaporation potential, such as mobile sand dunes, sandy loam and other sandy soils. In addition, shrubs with high tolerance to water stress are common in desert and desert steppe areas (Paruelo et al., 1999), making these ecosystems respond more readily to nutrients rather than water (Vitousek et al., 1991; Bai et al., 2008; Chen et al., 2009).

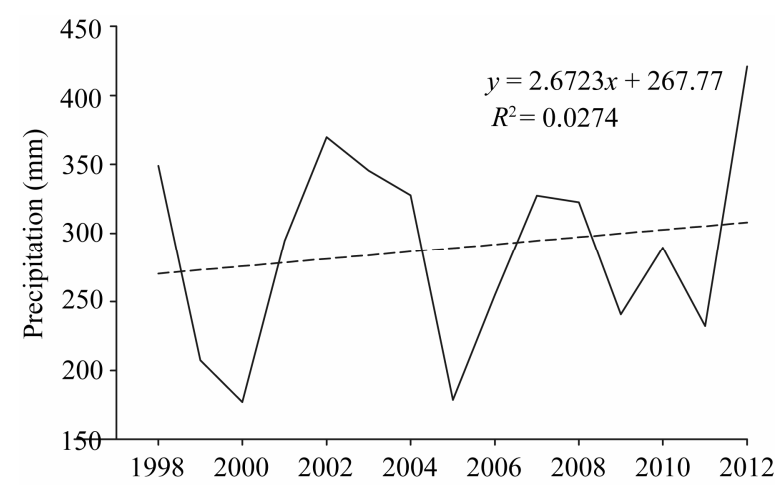

Fig. 6 Trends of mean annual growing season precipitation (from 11 weather stations) in the Ordos Plateau

\subsection{Human-induced vegetation increases}

Removing the precipitation effects on NDVI changes is helpful in identifying land degradation or improvement caused by human activities. In particular, higher positive regression slopes of MLM-Restrend and SLR-Restrend observed in the typical steppe and sandy land area of the eastern Ordos are associated with the intensification of land improvement projects and vegetation recovery. The goal of the Three-North Forest Shelterbelt Program (TNFSP) initiated in 1978 was to increase the vegetation cover for sand stabilization. Although the survival rate of planted trees and shrubs was low, it still resulted in an increase of the biomass in the eastern Ordos (Wang et al., 2010), which is also illustrated by our results. Airplane-based grass seeding took place in the 1980s and 1990s in some parts of the eastern Ordos to increase the vegetation cover and stabilize the sand dunes (Runnström, 2000). On the other hand, negative trends in residuals observed in the eastern Ordos are likely to be attributable to accelerating mineral resource extraction and the removal of vegetation in areas of open coal mining. 
Human-induced increases in vegetation cover in most parts of the Ordos are the direct consequence of changes in local household land management, which were instigated by two policy factors. The Household Production Responsibility System (HPRS) introduced in rural areas in the mid-1980s contracted public rangeland to households (Jiang, 2004) and contributed to increasing the biomass by planting trees and shrubs. The Prohibition of Open Grazing Policy (POGP) by the Ordos government became effective in 2000 and prohibited open grazing between April and June in rangelands and all year round in agricultural areas (Xin et al., 2008). Since most sheep were fed in pens with high densities, vegetation recovered from heavy grazing.

Lastly, our results showed no significant trend in vegetation changes in parts of the desert and desert steppe of the western Ordos (Figs. 4a and 5a). Therefore, it can be concluded that the role of human activities in modifying vegetation cover in these areas is small. Furthermore, scarce vegetation appears to be less responsive to highly variable precipitation.

\subsection{Comparison of MLM and SLR-Restrend analyses}

Our results showed that MLM-Restrend and SLRRestrend analyses can be effectively used to remove the effects of precipitation variation and detect human-induced land degradation or amelioration. When comparing the two approaches, MLM-Restrend was more accurate in detecting human activities, which was supported by ground-truthing.

NDVI responds differently to annual precipitation for different vegetation types, so a simple linear regression (SLR) used for the NDVI-rainfall relationship may lead to erroneous results when applied invariably to different vegetation types. For instance, shrubs with high tolerance to water stress are common in sandy land, desert steppe and desert area, and their water use efficiency (WUE) is very different from that of the plants in a typical steppe. It is recommended to fit separate models for vegetation types with different responses to precipitation (Omuto et al., 2010). On the other hand, MLM is capable of incorporating these variable NDVI-rainfall relationships.

MLM also has an advantage over SLR, which models NDVI-rainfall relationship as a single global function and thus cannot account for inter-annual fluctua- tions in precipitation (Verbesselt et al., 2010). Despite annual precipitation variability, the NDVI changes gradually at the landscape level and is best modeled as a linear trend. Because MLM is based on multi-scale, it can accommodate these discrepancies between scales of precipitation as well as human activities. This is supported by our study, which showed that MLM was more accurate in singling out the consequences of human activities on vegetation cover.

It was found that the methods used did not work sufficiently well in the desert and desert steppe of the western Ordos where most $\Sigma$ NDVI slopes and residual trends were not statistically significant. This can be explained by insignificant human economic activities and lower vegetation cover in these areas. The NDVI in scarcely vegetated areas is also known to be contaminated by a strong soil background. Therefore, factors such as soil and population density should be explored in the MLM modeling framework to improve the power of NDVI-rainfall models and detect the human-induced loss of vegetation in such arid ecosystems.

\section{Conclusions}

In this study, we used MLM of NDVI-rainfall relationships to detect human induced land degradation in Ordos Plateau of Inner Mongolia, China. Temporal trend analysis of $\Sigma$ NDVI suggests that re-vegetation was the dominant process in Ordos Plateau during the period of 1998-2012. Removing precipitation effects in NDVI time-series allowed us to identify areas of human induced vegetation cover increases or decreases. Vegetation increases reflect successful vegetation restoration projects and changes in land management in many parts of Ordos Plateau. MLM modeling allowed for more accurate detection of human-induced land degradation or amelioration than a simple linear regression. We found more factors should be included in MLM in order to improve its accuracy, which will be pursued in future research.

\section{Acknowledgements}

This study was supported by the National Basic Research Program of China (2012CB722201), the National Natural Science Foundation of China (30970504, 31060320), and the National Science and Technology Support Program (2011BAC07B01). 


\section{References}

Adamo S B, Crews-Meyer K A. 2006. Aridity and desertification: Exploring environmental hazards in Jáchal, Argentina. Applied Geography, 26(1): 61-85.

Bai Y, Wu J, Xing Q, et al. 2008. Primary production and rain use efficiency across a precipitation gradient on the Mongolia Plateau. Ecology, 89(8): 2140-2153.

Chen F, Zeng D, Fahey T. 2009. Changes in soil nitrogen availability due to stand development and management practices on semi-arid sandy lands in northern China. Land Degradation \& Development, 20(5): 481-491.

Evans J, Geerken R. 2004. Discrimination between climate and human-induced dryland degradation. Journal of Arid Environments, 57(4): 535-554.

Geerkena R, Ilaiwi M. 2004. Assessment of rangeland degradation and development of a strategy for rehabilitation. Remote Sensing of Environment, 90: 490-504.

Goldstein H. 2003. Multilevel Statistical Models. London: Wiley.

Huxman T, Smith M, Fay P, et al. 2004. Convergence across biomes to a common rain-use efficiency. Nature, 429(6992): 651-654.

Jiang H. 2004. Cooperation, land use, and the environment in Uxin Ju: the changing landscape of a Mongolian $\backslash$ Chinese borderland in China. Annals of the Association of American Geographers, 94(1): 117-139.

Knapp A K, Smith M D. 2001. Variation among biomass in temporal dynamics of aboveground primary production. Science, 291: $481-484$.

Li A, Wu J, Huang J. 2012. Distinguishing between human-induced and climate-driven vegetation changes: a critical application of RESTREND in inner Mongolia. Landscape Ecology, 27: 969-982.

Millington J D A, Perry G L W, Romero-Calcerrada R. 2007. Regression techniques for examining land use/cover change: a case study of a Mediterranean landscape. Ecosystems, 10(4): 562-578.

Nemani R, Keeling C, Hashimoto H, et al. 2003. Climate-driven increases in global terrestrial net primary production from 1982 to 1999. Science, 300(5625): 1560.

Nicholson S, Tucker C, Ba M. 1998. Desertification, drought, and surface vegetation: an example from the West African Sahel. Bulletin of the American Meteorological Society, 79(5): 815-829.

Omuto C T, Vargas R R, Alim M S, et al. 2010. Mixed-effects modelling of time series NDVI-rainfall relationship for detecting human-induced loss of vegetation cover in drylands. Journal of Arid Environments, 74(11): 1552-1563.

Paruelo J, Lauenroth W, Burke I, et al. 1999. Grassland precipitation-use efficiency varies across a resource gradient. Ecosystems, 2(1): 64-68.

Pickup G. 1996. Estimating the effects of land degradation and rainfall variation on productivity in rangelands: an approach using remote sensing and models of grazing and herbage dynamics. Journal of Applied Ecology, 33(4): 819-832.

Raudenbush S W, Bryk A S. 2002. Hierarchical Linear Models.
Thousand Oaks, GA: Sage Publication.

Reynolds J F, Stafford Smith M. 2002. Global desertification: do humans create deserts? In: Stanfford-Smith M, Reynolds J F. Do Humans Create Deserts? Berlin: Dahlem University Press, 1-22.

Reynolds J F, Smith D M S, Lambin E F, et al. 2007. Global desertification: building a science for dryland development. Science, 316(11): 847-851.

Runnström M C. 2000. Is northern China winning the battle against desertification? satellite remote sensing as a tool to study biomass trends on the Ordos Plateau in Semiarid China. Ambio, 29(8): $468-476$

Serneels S, Linderman M, Lambin E. 2007. A multilevel analysis of the impact of land use on interannual land-cover change in East Africa. Ecosystems, 10(3): 402-418.

Singer J D. 1998. Using SAS PROC MIXED to fit multilevel models, hierarchical models, and individual growth models. Journal of Educational and Behavioral Statistics, 23(4): 323-355.

Snijders T A B, Bosker R J. 1999. Multilevel Analysis: An Introduction to Basic and Advanced Multilevel Modelling. New York: Sage.

UNCCD. 1994. Elaboration of an International Convention to Combat Desertification in Countries Experiencing Serious Drought and/or Desertification, Particularly in Africa. United Nations: United Nations Convention to Combat Desertification.

UNCED. 1992. Managing Fragile Ecosystems: Combating Desertification and Drought. United Nations, New York: United Nations Conference on Environment and Development.

Verbesselt J, Hyndman R, Newnham G, et al. 2010. Detecting trend and seasonal changes in satellite image time series. Remote Sensing of Environment, 114(1): 106-115.

Vitousek P, Howarth R. 1991. Nitrogen limitation on land and in the sea: how can it occur? Biogeochemistry, 13(2): 87-115.

Wang X M, Zhang C X, Hasi E, et al. 2010. Has the Three Norths Forest Shelterbelt Program solved the desertification and dust storm problems in arid and semiarid China? Journal of Arid Environments, 74(1): 13-22.

Wessels K J, Prince S D, Malherbe J, et al. 2007. Can human-induced land degradation be distinguished from the effects of rainfall variability? a case study in South Africa. Journal of Arid Environments, 68(2): 271-297.

Wu J, Li H. 2006. Concepts of scale and scaling. In: Wu J, Jones K B, Li $\mathrm{H}$, et al. Scaling and Uncertainty Analysis in Ecology: Methods and Applications. Netherlands: Springer, 3-15.

Xin Z, Xu J, Zheng W. 2008. Spatiotemporal variations of vegetation cover on the Chinese Loess Plateau (1981-2006): Impacts of climate changes and human activities. Science in China, Series D: Earth Sciences, 51(1): 67-78.

Zang S Y, Huang X. 2006. An aggregated multivariate regression land-use model and its application to land-use change processes in the Daqing region (northeast China). Ecological Modelling, 193(3-4): 503-516. 